\title{
Health Status, Stress and Life Satisfaction in a Community Population with MS
}

\author{
Scott B. Patten, Jeanne V.A. Williams, Dina H. Lavorato, Sandy Berzins, \\ Luanne M. Metz, Andrew G.M. Bulloch
}

\begin{abstract}
Background: Community-based studies can describe health status and related variables in people with Multiple Sclerosis (MS) while avoiding biases introduced by help-seeking in specific clinical settings. Objective: To describe general health status, stress perceptions and life satisfaction in people with MS, in comparison to those with other types of disabilities. Materials \& Methods: The Participation and Activity Limitation Survey (PALS) was a post-censual survey conducted by Statistics Canada in association with the 2006 Canadian Census. PALS collected data from a random sample of $n=22,513$ respondents identified as having health-related impairments. Frequencies and quartiles as well as mean values, along with associated $95 \%$ confidence intervals, were calculated in the analysis. Results: PALS identified 245 individuals with MS. Health status, both perceived and when weighted for societal preference, was markedly lower than that of other disabled groups. No differences in self-perceived stress were seen. People with MS reported lower levels of satisfaction with their health but slightly higher levels of satisfaction with their family and friends. Conclusions: People with MS report lower levels of general health status and more impairment than those with other disabling conditions. Higher levels of satisfaction with friends and family may reflect psychological adaptation to the illness.
\end{abstract}

RÉSUMÉ: État de santé, stress et satisfaction dans la vie chez une population communautaire atteinte de la SP. Contexte : Les études communautaires peuvent décrire l'état de santé et les variables qui s'y rattachent chez les individus atteints de la SP tout en évitant les biais rencontrés dans les études faites dans des contextes cliniques spécifiques. Objectif : Le but de l'étude était de décrire l'état général de santé, la perception du stress et la satisfaction dans la vie chez des individus atteints de la SP et de les comparer à des individus ayant d'autres types d'invalidités. Méthode : L'Enquête sur la participation et les limitations d'activités (EPLA) est une enquête de Statistique Canada associée au recensement canadien de 2006. L'EPLA a recueilli des données chez un échantillon pris au hasard comprenant 22513 répondants identifiés comme ayant des problèmes de santé. Nous avons calculé les fréquences, les quartiles, les valeurs moyennes ainsi que les intervalles de confiance à 95\%. Résultats : L'EPLA a identifié 245 individus atteints de la SP. Leur état de santé perçu et pondéré pour les préférences sociétales était significativement plus bas que celui d'autres groupes ayant des handicaps. Aucune différence n'a été observée en ce qui a trait au stress perçu. Les individus atteints de la SP ont rapporté des niveaux plus bas de satisfaction au sujet de leur santé, mais des niveaux légèrement plus élevés de satisfaction concernant leur famille et leurs amis. Conclusions : Les individus atteints de la SP rapportent des niveaux plus bas de santé général et plus d'invalidité que ceux qui sont atteints d'autres maladies invalidantes. Des niveaux plus élevés de satisfaction concernant les amis et la famille pourraient refléter l'adaptation psychologique à la maladie.

Can J Neurol Sci. 2012; 39: 206-212

Although Multiple Sclerosis (MS) is the most common disabling neurological condition in young people ${ }^{1}$ it is sufficiently rare that population-based studies are difficult to carry out. Studies conducted in clinical settings may be influenced by a higher level of severity or morbidity in those populations or by particular characteristics of patients seeking treatment in those settings. Most studies of subjectively assessed health status in community populations have used clinic or health-system rosters to identify their samples ${ }^{2,3}$ and for this reason may not provide an accurate description of the general population with MS. A study by Gottberg et $\mathrm{al}^{4}$ sampled from a variety of settings in a purposeful effort to obtain a representative sample. Quality of life ratings were compared to general population norms and found to be lower in all domains covered by the EQ-5D: mobility, self-care, usual activities, pain/discomfort and anxiety/depression. However, the EQ-5D has questionable construct and criterion validity in MS, and fails to differentiate moderate from more severe illness. ${ }^{5}$ The only

From the Department of Community Health Science (SBP, JVAW, DHL, SB), Department of Clinical Neurosciences (LMM), Mental Health Centre for Research and Education, Hotchkiss Brain Institute (SBP, AGMB), University of Calgary, Calgary, Alberta, Canada.

Received July 5, 2011. Final Revisions Submitted September 20, 2011 Correspondence to: Scott Patten, Department of Community Health Sciences, 3rd Floor TRW Building, University of Calgary, 3280 Hospital Drive NW, Calgary, Alberta, T2N 4Z6, Canada. 
study to examine health status in a direct community sample was conducted in Canada, and reported by Jones et $\mathrm{al}^{6}$ and Pohar et al. ${ }^{7}$ This study used data from the Canadian Community Health Survey, iteration 1.1 (CCHS 1.1). People with MS were found to have dramatically lower health utility ratings, as assessed by the Health Utility Index ${ }^{8}$, and lower self-rated health than the general population.

Perhaps because population-based studies of MS are difficult to conduct it appears that the CCHS 1.1 studies are the only ones to directly compare quality of life and perceived health in a probability sample with and without MS. Additional descriptive information would be valuable to have, particularly data collected from other samples, and incorporating other comparison groups. An opportunity to examine perceived health status in a community cohort with MS arises from a Canadian post-censual survey called the Participation and Activity Limitations Survey (PALS) ${ }^{9}$. This survey is based on a probability sample of respondents reporting health-related impairments during a national census in 2006. Conditions responsible for impairment were recorded, supporting a diseasespecific description of health status. The survey's linkages to a national census allow population-based inferences to be made concerning community-dwelling residents with MS and also support comparisons with people having health-related impairments of other causes.

In this analysis, we were interested in examining general perceptions of overall health status, broadly defined, in people with MS. Our definition extended beyond self perceived heath status to preference waited health status and to include stress and satisfaction with life. One goal of the study was to provide a quantitative description of the impact of MS as compared to other disabling health conditions. Participation and Activity Limitations Survey allows this to be done with a community sample, lowering the risk of bias that may result from the use of clinical samples.

The Participation and Activity Limitations Survey data are also useful for assessing the possibility that people with MS may perceive their illness in ways that are discordant with others' perceptions. Such positive perceptions may be related, for example, to euphoric mental states long believed to be associated with this condition ${ }^{10}$. Positively biased perceptions would, for example, be evident in the form of discordance between overall health status ratings made by people with MS and those arising from instruments that apply societal preference weights. Preference weights (also known as utility weights) reflect the value that members of the general population place on particular health states.

\section{Materials ANd Methods}

In a Canadian Census conducted in 2006, $80 \%$ of households received a short-form questionnaire that contained eight basic questions. The remaining, randomly sampled, $20 \%$ received a more detailed measure that contained 61 questions (the census "long-form") 11, a copy of which may be found on the Statistics Canada website ${ }^{12}$. Questions on the long-form were usually answered by a single household informant providing information about all residents of the household.

The long-form contained two questions concerning healthrelated impairments: "Does this person have any difficulty hearing, seeing, communicating, walking, climbing stairs, bending, learning or doing any similar activities?" This question was followed by "Does a physical condition or mental condition or health problem reduce the amount or the kind of activity this person can do: (a) at home? (b) at work or at school? (c) in other activities, for example, transportation or leisure?" Respondents providing affirmative responses to one or more of these items were used in development of a sampling frame for the PALS survey. The selection of the PALS sample from this frame used stratified random sampling to ensure feasibility of estimation both by province/territory and age group. Severity of reported disability was also included as a stratification factor during sampling $^{12}$.

Because it was linked to the Census, the PALS sampling frame covered persons living in private and some collective households in the ten provinces and the three territories of Canada. Populations living on First Nations reserves were excluded as well as residents of institutional collectives, military bases, Canadian Armed Forces vessels, merchant vessels and coast guard vessels, as well as campgrounds and parks.

Data were collected primarily by computer assisted telephone interview. For analytical purposes, a stratified random sample of 107,400 adults was also selected from the general census frame. This sample consisted of individuals who had no disability or activity limitations according to the census. This analytical sample was allocated proportional to population size in order to support projection of some PALS estimates to the general population. Unfortunately, since no additional data were collected from the analytical sample, the ability to make estimates was restricted to specific items on the census form. Deterministic imputation for missing data was carried out in specific circumstances by Statistics Canada, but only when sufficient information was available from related questions ${ }^{9}$. Proxy responses were also allowed. However, proxies were only used after "every effort" had been made to contact and interview respondents directly. If a respondent was not available when the interviewer called, multiple follow-up attempts were made ${ }^{13}$. The proxy rate among those aged 15 (the group eligible for the current study) and above in PALS was $12 \% 13$.

Overall perceived health was evaluated using an item with the following wording: "In general, would you say your health is..." with response options being: excellent, very good, good, fair and poor. The PALS survey included a questionnaire called the Comprehensive Health Status Measurement System (CHSMS). This questionnaire classifies health status into levels that can be linked to societal preference weights by a societal preference index called the Health Utility Index, Mark 3 (HUI3 ). These weights correspond to societal preferences for various types of health states, as determined by a household survey and standard gamble methodologies ${ }^{14}$. With conventional scoring of the HUI scale, a score of one indicates perfect health whereas a score of zero represents a health state judged to be equivalent to death. The health utilities calculated by Statistics Canada allow the scale to assume values less than zero, corresponding to health states valued as being worse than death.

Stress was assessed by a single item with the following wording: "Thinking about the amount of stress in your life, would you say that most days are...?" Response options were: not at all stressful, not very stressful, a bit stressful, quite a bit 
stressful and extremely stressful. Assessment of life satisfaction used a ten-point scale, where 1 meant "very dissatisfied" and 10 meant "very satisfied." Respondents were asked to rate their satisfaction in five areas: relationships with family members, relationships with friends, with their health, with their job or main activity, and with the way they spend their time.

As an index of comparison, some weighted general population estimates are reported in this paper. These are estimates deriving from the public use microdata file for iteration 4.1 of a general health survey called the Canadian Community Health Survey (CCHS $)^{15}$ and they were age and sex standardized to the PALS sample, and to the subset of PALS respondents with MS in order to ensure demographic comparability. The CCHS was conducted using a representative sample drawn from the population of household residents. This iteration of the CCHS was conducted at approximately the same time as PALS, with data collection occurring in 2007 and 2008. As this was a separate survey, no attempt was made to make statistical comparisons between PALS and CCHS, the estimates were presented strictly to facilitate qualitative comparisons.

Participation and Activity Limitations Survey incorporated complex design features including stratified sampling (unequal selection probabilities). Statistics Canada develops sampling weights that account for these design features and support unbiased estimation of statistical parameters and their associated 95\% confidence intervals. Such confidence intervals for proportions and means were the main analytical method employed in this analysis. Some p-values, also incorporating these sampling weights, are also reported. When highly skewed distributions were encountered in the HUI data, quartiles were calculated in order to provide a description of the distribution of ratings. The quartile-based approach was chosen in order to provide finer descriptive gradation than could be achieved with a dichotomous division of scores, as employed by some previous authors $^{6,7}$. This was considered important because mean HUI scores less than 0.7 accompany Expanded Disability Status Scale $(\text { EDSS })^{16}$ scores greater than 1 or 2 whereas mean HUI scores decline across the whole range of EDSS scores. Adjustments to the sampling weights for non-response were also made by Statistics Canada, reducing the risk of bias due to nonresponse. All analyses were performed using Stata $11^{17}$ at the Prairie Regional Research Data Centre on the University of Calgary campus (http://www.ucalgary.ca/IR/RDC/). The project was approved by the University of Calgary Conjoint Ethics Review Board.

\section{Results}

The number of sampled respondents aged 15 or older for PALS was 38,839 . There was a response rate of approximately $73 \%$, leading to an actual sample of 28,640 respondents. Upon contacting these individuals for the PALS survey, health-related impairments were confirmed for 22,513 (79\%) of the respondents. The analysis reported here used the subset of respondents with confirmed health-related impairment. The discrepancy between those apparently eligible and those confirmed to have health-related impairments arose primarily because some respondents had short-lived health issues that had resolved by the time they were contacted for PALS. There were 245 people with MS in the sample. People with MS represented $1.1 \%$ of the PALS sample. Under the unrealistic assumption that no members of the population not screening into PALS had MS, this would translate into a weighted population prevalence estimate of $0.2 \%$ (200 per 100,000$)$. As there are people with MS

Table: PALS sample compared to the general population

\begin{tabular}{|c|c|c|c|c|}
\hline \multirow[t]{2}{*}{ Variable Name } & \multirow[t]{2}{*}{ Categories } & \multirow{2}{*}{$\begin{array}{l}\text { PALS Sample } \\
\text { With MS } \\
\% \\
(n=245)\end{array}$} & \multirow{2}{*}{$\begin{array}{l}\text { PALS Sample } \\
\text { Without MS } \\
\% \\
(n=22,268)^{a}\end{array}$} & \multirow{2}{*}{$\begin{array}{l}\text { General Population } \\
\% \\
(n=136,040)^{b}\end{array}$} \\
\hline & & & & \\
\hline \multirow[t]{2}{*}{ Sex } & Male & 28.5 & 45.2 & 48.6 \\
\hline & Female & 71.5 & 54.8 & 51.4 \\
\hline \multirow[t]{2}{*}{ Age Group } & $15-44$ years & 23.8 & 21.1 & 50.5 \\
\hline & $45+$ years & 76.2 & 78.9 & 49.5 \\
\hline \multirow[t]{3}{*}{ Marital Status } & Married $^{c}$ & 59.8 & 56.1 & 59.5 \\
\hline & Single & 20.0 & 16.1 & 27.0 \\
\hline & Previously married $^{d}$ & 20.2 & 27.7 & 13.6 \\
\hline \multirow[t]{2}{*}{ Education } & Less than secondary & 38.5 & 58.2 & 49.0 \\
\hline & Secondary level or more & 61.5 & 41.8 & 51.0 \\
\hline \multirow[t]{3}{*}{ Employment $^{\mathrm{e}}$} & Worked & 26.3 & 26.5 & 61.5 \\
\hline & Did not work & 35.6 & 52.1 & 12.0 \\
\hline & Completely unable & 38.0 & 21.4 & 26.6 \\
\hline
\end{tabular}




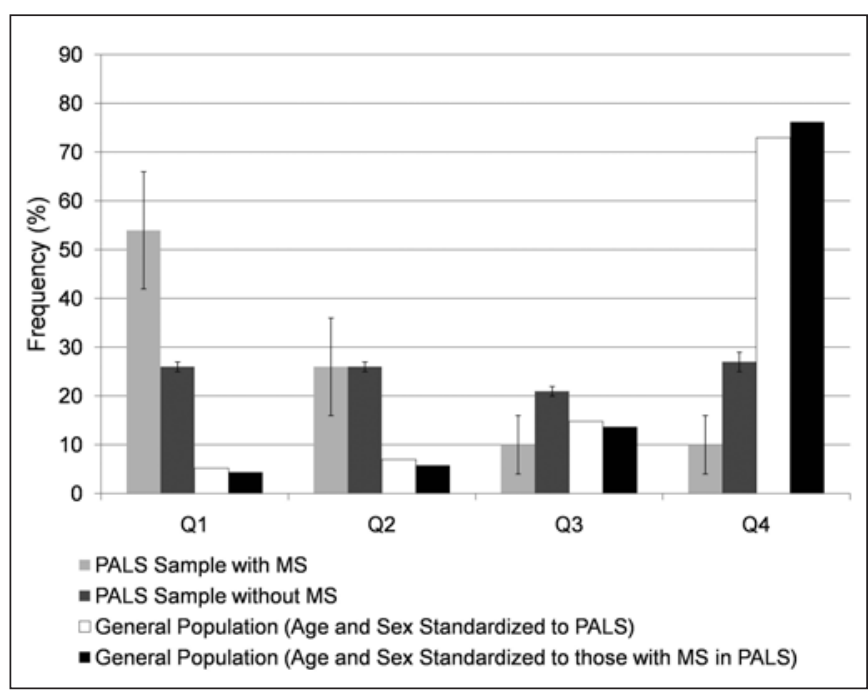

Figure 1: Frequency of HUI Scores*, by Approximate Participation and Activity Limitations Survey (PALS) Sample Quartiles*** HUI = Health Utility Index (Mark 3). Error bars represent $95 \%$ confidence intervals. ** the boundaries for the quartiles were determined using the entire PALS sample, see text for details. General population estimates derive from the 2007/2008 Canadian Community Health Survey, estimates based on $n=22,514$ available responses. These are directly standardized to the age and sex distribution of the PALS participants and the subset of these with MS.

who are not impaired, this is almost certainly an underestimate of the prevalence of MS in Canada. The proportion of proxy respondents in PALS was the same (12\%) in those with and without MS. As the general population analytical sample contained basic information collected in the census, those with MS could be compared to the general population on several demographic variables. In the PALS sample, people with MS were more likely to be female (72\% as compared to $51.4 \%$ in the general population) and less likely to be employed at the time of survey (26\% working as compared to $62 \%$ of the general population). The Table provides a summary of the sample's demographic features.

The non-MS portion of the PALS sample reported a diverse set of conditions, and a large proportion reported that more than one condition was contributing to their impairment. The first reported conditions most often fell into the ICD-10 category of musculoskeletal system and connective tissue diseases (51.5\%), but sensory impairments were also commonly reported $(11.0 \%)$ as were diseases of the circulatory system $(7.5 \%)$. The first reported disabling condition was a disease of the nervous system for $5.3 \%$ of the sample. Within this group the most commonly reported condition was MS (21.9\% of this group) and the second most common was Parkinson's disease (12.6\% of this group).

The distribution of HUI scores in the PALS sample was right skewed, particularly in the subset of respondents without MS. Therefore, for most analysis, we divided the HUI ratings into approximate quartiles defined with reference to the entire PALS sample. The lower quartile of HUI scores included the range of -0.34 to $<0.44$. The lower quartile defines a more restricted group than that of Horsman et al, who recommended use of HUI-

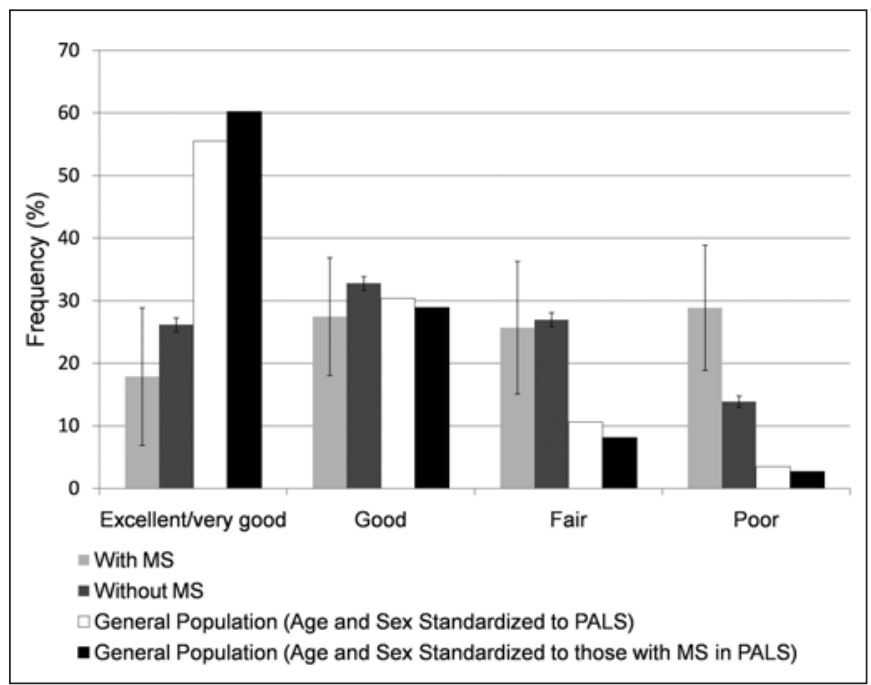

Figure 2: Perceived Health in the Participation and Activity Limitations Survey (PALS) Sample, by MS Status. Error bars represent 95\% confidence intervals. General population estimates derive from the 2007/2008 Canadian Community Health Survey, estimates based on $n=$ 22,514 available responses. These are directly standardized to the age and sex distribution of the PALS participants and the subset of these with $M S$.

$3<0.70$ to indicate "severe" impairment ${ }^{8}$. The lower-middle quartile was 0.45 to $<0.73$, so the Horsman et al definition applies to approximately half of those with MS. The upper middle quartile was 0.73 to $<0.90$ and the upper quartile included those with scores greater than or equal to 0.90 . Figure 1 presents frequency distributions, by quartile, for people with and without MS in PALS. A much larger proportion of those with MS fall into the lowest quartile category. In order to contrast both groups with the general population, age and sex standardized estimates from the Canadian Community Health Survey have been added to the graph, as described above. The proportion of those with MS having lower quartile HUI ratings is approximately twice that of those without MS and several orders of magnitude higher than the general population. Of PALS participants with MS 8.8\% (95\% CI 3.2 - 14.4) reported health status associated with societal preference-weighted utilities lower than death, compared to $3.7 \%$ (95\% 3.1 - 4.2) in the rest of the PALS sample.

The pattern for self-perceived health status resembled that of the HUI. Figure 2 presents the distribution of perceived health ratings in people with and without MS. People with MS are less likely to rate their health as excellent and approximately twice as likely to rate their health as poor as are PALS respondents without MS. Figure 2 also shows, for purposes of comparison, age and sex standardized estimates from the CCHS. Figure 3 presents the frequency distribution of perceived stress levels in people with and without MS. Figure 3 does not suggest that people with MS find their life to be more stressful than those with other disabling conditions, or the general population.

Figure 4 shows mean life satisfaction ratings among PALS respondents with and without MS across the five domains of life satisfaction assessed in PALS. Respondents with MS reported 


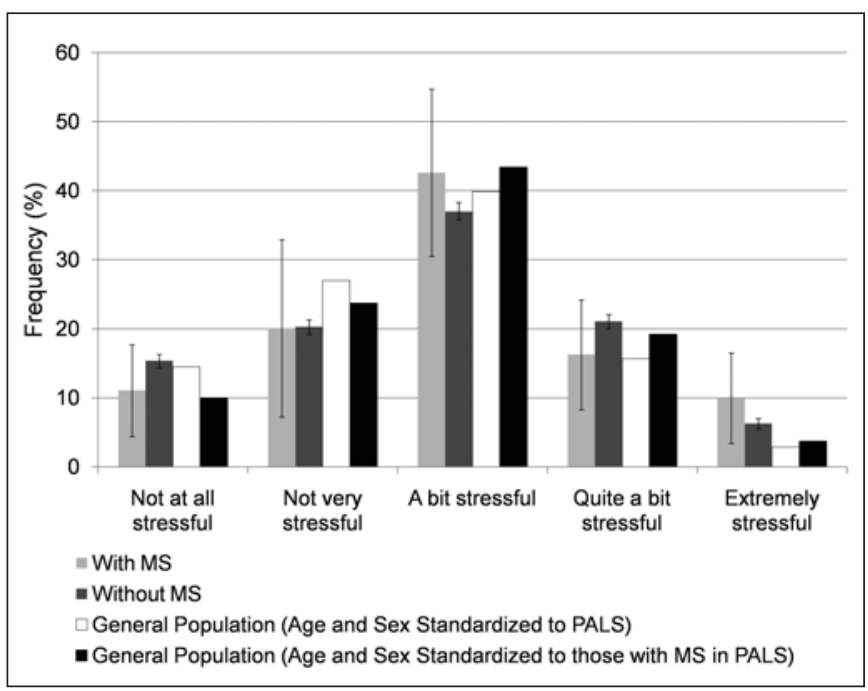

Figure 3: Stress Ratings, by MS Status in the Participation and Activity Limitations Survey (PALS). Error bars represent 95\% confidence intervals. General population estimates derive from the 2007/2008 Canadian Community Health Survey, estimates based on $n=22,514$ available responses. These are directly standardized to the age and sex distribution of the PALS participants and the subset of these with MS.

slightly lower satisfaction with their health, their jobs (when applicable) and how they spend their time than did persons with other conditions. Interestingly, they reported slightly higher satisfaction with their family. The association of MS with greater satisfaction with family remained statistically significant in a linear regression model adjusting for HUI quartile $(p=0.001)$. A linear regression model predicting satisfaction with friends in association with MS and adjusting for HUI quartile identified an interaction between HUI score and MS $(\mathrm{p}=0.04)$. Those in

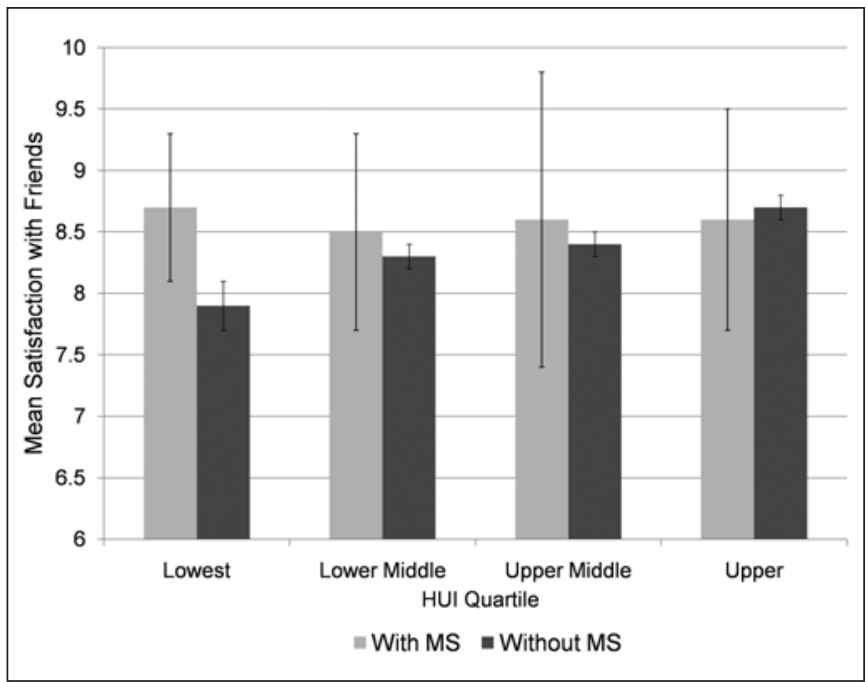

Figure 5: Mean Satisfaction with Friends, by MS Status and HUI* Quartile. *HUI = Health Utility Index (Mark 3). Error bars represent $95 \%$ confidence intervals.



Figure 4: Life Satisfaction in Participation and Activity Limitations Survey (PALS) Participants with and Without MS. Error bars represent $95 \%$ confidence intervals.

lower health status categories (as defined by HUI quartile) had higher satisfaction with their friends when they had MS as opposed to other conditions; the interaction is apparent in a graphical depiction of the frequency distribution, see Figure 5. In those without MS, satisfaction with family declines with worsening health status, whereas this did not occur in people with MS.

A similar pattern was seen for satisfaction with family (see Figure 6) although the interaction was not statistically significant. After adjustment for HUI score, none of the other categories of life satisfaction remained significantly associated

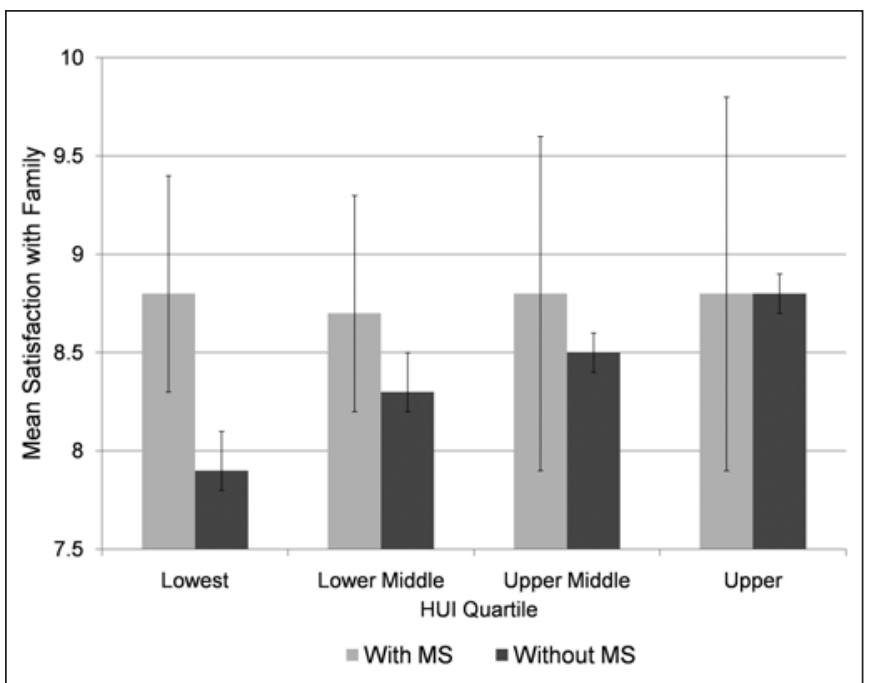

Figure 6: Mean Satisfaction with Family, by MS Status and HUI* Quartile. ${ }^{*} H U I=$ Health Utility Index (Mark 3$)$. Error bars represent $95 \%$ confidence intervals. 


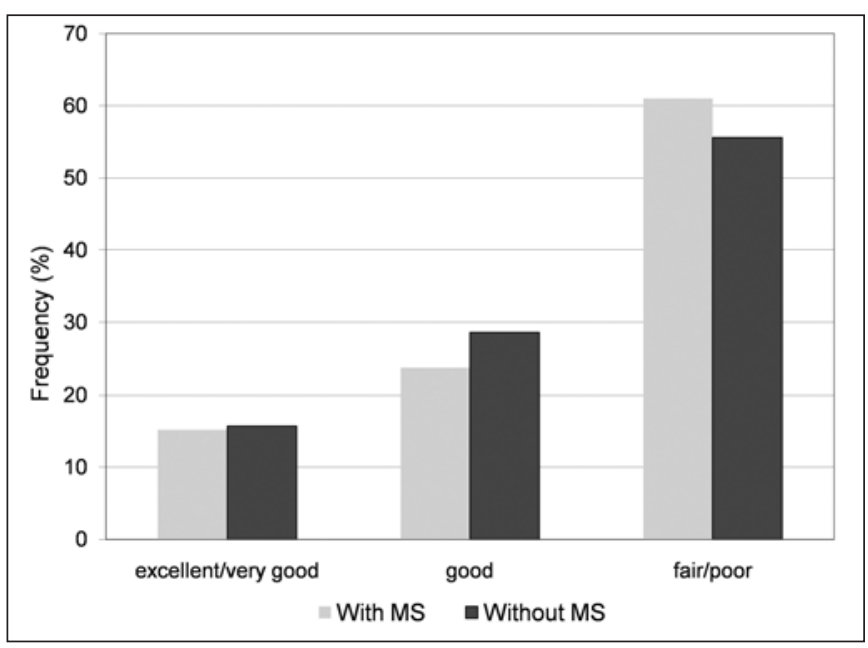

Figure 7: Perceived Health, by MS in Participation and Activity Limitations Survey (PALS) Participants with Below-median HUI* Ratings. $* H U I=$ Health Utility Index (Mark 3). Error bars represent 95\% confidence intervals.

with MS status: health $(p=0.72)$, jobs $(p=0.76)$ nor time spent $(\mathrm{p}=0.12)$.

In order to examine discordance between perceived health and societal weighted health status, perceived health was tabulated according to whether a respondent was above or below the median HUI rating in the PALS dataset (cross-tabulation at the quartile level was not possible due to sample size constraints). If people with MS were to perceive their health status more positively than others having similar deficits, a divergence between these two sets of ratings would be expected because the HUI values represent the perceptions of the average person of the value of a particular health state. The patterns, however, were similar both for those above and below the HUI median. Figure 7 shows percentage ratings for self-perceived health in persons with and without MS and who had HUI ratings below the median value. There are no substantial differences in health perceptions among person with MS after stratification for overall health status. A similar pattern was seen in respondents with above-median HUI ratings, see Figure 8.

\section{DISCUSSION}

This study examined global indicators of health status in a community sample of people with impairments due to MS. Generally, respondents with MS tended to report lower levels of health than people with other types of disabling conditions. This was true both for perceived health status and for HUI scores, which incorporate societal preference weights. This finding does not support the idea that people with MS subjectively perceive their deficits in a way that is markedly differently than what others would perceive. People with MS reported slightly higher satisfaction with their families and friends than did people with other disabling conditions. In MS, satisfaction with friends appeared not to decline in association with more severe illness, as was seen in PALS respondents without MS.



Figure 8: Perceived Health, by MS in PALS Participants with Abovemedian HUI* Ratings. *HUI = Health Utility Index (Mark 3). Error bars represent $95 \%$ confidence intervals.
The PALS dataset is not sufficiently detailed to further explore the basis for differences seen in life satisfaction. Speculatively, it is possible that family and friends are actually more supportive of people with MS than they are of people with disabilities due to other causes. One may also speculate that, as a component of adaptation to illness, people with MS may place greater value on friends and family and consequently derive greater life satisfaction from them. The occurrence of euphoric states in some people with advanced $\mathrm{MS}^{10}$ would seem to be an unlikely explanation for the result, as higher satisfaction was not observed across other categories (health, job, time spent) in people with MS.

These results highlight the seriousness of the challenges facing people with MS from the point of view of their perceived health status. Whereas among people with other disabling conditions the modal overall self-perception of health status was "good", in people with MS it was "poor." Nearly 10\% of community residents with impairments due to MS reported a health state that, by societal preference standards, was judged worse than death. These findings replicate earlier results comparing people with MS to others in a general population sample ${ }^{6}$. As such, the results extend the results of a previous Canadian study that compared the health status of people with MS to that of a general population sample. In that study, striking differences were seen. The current analysis shows that even within the subset of the household population reporting health related impairments, the health status of people with MS remains dramatically worse. The results also help to document the burden of disability that is attributable to MS, as $1 \%$ of the population having health impairments in the general population had MS and their health status was much lower than the others. The finding that nearly $10 \%$ of those with MS reported a health state worse than death is also a striking indicator of the seriousness of MS (less than one half of one percent of the general household 
population reporting this) and may point towards a factor contributing to the high frequency of suicide seen in people with $\mathrm{MS}^{18-20}$.

The PALS survey is subject to several substantial limitations. One is that the study includes respondents that "screened in" because they had impairments of various types. The many people with MS who are not impaired are not reflected in this study; unfortunately, the proportion of people with MS in the community who are unimpaired is unknown. The component of the PALS sample without MS was highly heterogeneous, making the comparisons presented somewhat tenuous. As PALS was not an MS study, no disease-specific content (e.g. Expanded Disability Status Scale) was included. However, it is interesting to note that the HUI correlates (-0.77: higher HUI scores being seen with lower EDSS values) fairly strongly with EDSS ratings. Another weakness is a general lack of validated measures in PALS. Several of the variables incorporated in this analysis were evaluated only by single items. Statistics Canada, however, did conduct extensive field testing of the items, including obtaining focus group input to help ensure validity of the responses. Although the PALS interview had a module for household variables, it provided little data about living arrangements. This is another limitation of the current analysis. Because people with MS who were free of impairment were probably also underrepresented such that the PALS sample may have been biased towards those with more negative health status. On the other hand, as the PALS estimates do not include institutionalized respondents so there may be a bias the other direction. It is difficult to know which potential source of bias would predominate. It is therefore important that these results be replicated. It must also be acknowledged that many of the estimates presented are imprecise due to sample size limitations. Despite these weaknesses, however, the PALS estimates provide a valuable perspective as they are likely to be free of bias resulting from medical help-seeking or from the practices and policies of specific clinical services.

\section{ACKNOWLEDGEMENTS}

This analysis was based on data collected by Statistics Canada, but the results and conclusions do not represent the opinions of Statistics Canada. None of the authors have conflicts of interest to declare. Dr. Patten is a Senior Health Scholar with Alberta Innovates, Health Solutions. Ms. Berzins was funded by an EndMS Studentship. This study was funded by an operating grant from Alberta Addiction and Mental Health Partnership Program's Collaborative Research Grants Initiative. (http://www.mentalhealthresearch.ca/KeyInitiatives/Research Gr ants/Pages/default.aspx).

\section{REFERENCES}

1. Murray TJ. Diagnosis and treatment of multiple sclerosis. BMJ. 2006;332(7540):525-7.

2. Khan F, McPhail T, Brand C, et al. Multiple sclerosis: disability profile and quality of life in an Australian community cohort. Int J Rehabil Res. 2006;29(2):87-96.

3. Solari A, Radice D. Health status of people with multiple sclerosis: a community mail survey. Neurol Sci. 2001;22(4):307-15.

4. Gottberg K, Einarsson U, Ytterberg C, et al. Health-related quality of life in a population-based sample of people with multiple sclerosis in Stockholm County. Mult Scler. 2006;12(5):605-12.

5. Fisk JD, Brown MG, Sketris IS, et al. A comparison of health utility measures for the evaluation of multiple sclerosis treatments. J Neurol Neurosurg Psychiatry. 2005;76(1):58-63.

6. Jones CA, Pohar SL, Warren S, et al. The burden of multiple sclerosis: a community health survey. Health Qual Life Outcomes. 2008;6:1

7. Pohar SL, Jones CA, Warren S, et al. Health status and health care utilization of multiple sclerosis in Canada. Can J Neurol Sci. 2007;(2):167-74.

8. Horsman J, Furlong W, Feeny D, et al. The Health Utilities Index (HUI): concepts, measurement properties and applications. Health Qual Life Outcomes. 2003;1:54.

9. Statistics Canada. Participation and Activity Limitation Survey (PALS). < [05] Last Update [cited 2011 Sep 15]; Available from: URL: http://www.statcan.gc.ca/cgi-bin/imdb/p2SV.pl?Function= getSurvey \&SDDS $=3251 \&$ lang $=$ en $\& \mathrm{db}=\mathrm{imdb} \& \mathrm{adm}=8 \& \mathrm{dis}=2 \# \mathrm{a} 2$

10. Finger S. A happy state of mind. A history of mild elation, denial of disability, optimism, and laughing in multiple sclerosis. Arch Neurol. 1998;55(2):241-50.

11. Statistics Canada. Overview of the census. [cited 2011 Sep 15]; Available from: URL: http://www12.statcan.gc.ca/censusrecensement/2006/ref/dict/overview-apercu/pop1-eng.cfm

12. Statistics Canada. 2006 Census Long Form. < [05] Last Update[cited 2011 Sep 15]; Available from: URL: http:// www.statcan.gc.ca/imdb-bmdi/instrument/3901_Q2_V3eng.pdf

13. Statistics Canada. The 2006 Participation and Activity Limitation Survey: Disability in Canada. Data collection. [cited 2011 Sep 15]; Available from: URL: http://www.statcan.gc.ca/pub/89628-x/2007001/4124990-eng.htm

14. Furlong WJ, Feeny DH, Torrance GW, et al. Multiplicative multiattribute utility function for the Health Utilities Index Mark 3 (HUI3) system: a technical report. 1998. Report No.: McMaster University Centre for Health Economics and Policy Analysis Working Paper \#98-11.

15. Statistics Canada. Canadian Community Health Survey - Annual Component (CCHS). [cited 2011 Sep 15]; Available from: URL: http://www.statcan.gc.ca/cgi-bin/imdb/p2SV.pl?Function $=$ getSurvey $\&$ SDDS $=3226 \&$ lang $=e n \& d b=i m d b \& a d m=8 \&$ dis $=2$

16. Kurtzke JF. Rating neurologic impairment in multiple sclerosis: an expanded disability scale (EDSS). Neurology. 1983;33(11): 1444-52.

17. Stata, version 11.0 [computer program]. Version 11.0. College Station, TX: Stata Corporation; 2009.

18. Brønnum-Hansen H, Stenager E, Stenager EN, et al. Suicide among Danes with multiple sclerosis. J Neurol Neurosurg Psychiatry. 2005;76(10):1457-9.

19. Stenager EN, Stenager E, Koch-Henriksen N, et al. Suicide and multiple sclerosis: an epidemiological investigation. J Neurol Neurosurg Psychiatry. 1992;55(7):542-5.

20. Feinstein A. Multiple sclerosis, depression, and suicide. Clinicians should pay more attention to psychopathology. BMJ. 1997;315 (7110):691-2. 